\title{
GCD Regimen
}

National Cancer Institute

\section{Source}

National Cancer Institute. GCD Regimen. NCI Thesaurus. Code C37605.

A chemotherapy regimen consisting of gemcitabine, carboplatin and dexamethasone that can be used as salvage therapy for relapsed/refractory lymphoma. 